\title{
Sea Ice Type Concentration From Mizex-87 Sar Data
}

\section{Skriver, Henning}

Published in:

International Geoscience and Remote Sensing Symposium

Publication date:

1991

Document Version

Publisher's PDF, also known as Version of record

Link back to DTU Orbit

Citation (APA):

Skriver, H. (1991). Sea Ice Type Concentration From Mizex-87 Sar Data. In International Geoscience and Remote Sensing Symposium: Remote Sensing: Global Monitoring for Earth Management. (Vol. Volume 2, pp. 415-418). IEEE.

\section{General rights}

Copyright and moral rights for the publications made accessible in the public portal are retained by the authors and/or other copyright owners and it is a condition of accessing publications that users recognise and abide by the legal requirements associated with these rights.

- Users may download and print one copy of any publication from the public portal for the purpose of private study or research.

- You may not further distribute the material or use it for any profit-making activity or commercial gain

- You may freely distribute the URL identifying the publication in the public portal

If you believe that this document breaches copyright please contact us providing details, and we will remove access to the work immediately and investigate your claim 


\title{
SEA ICE TYPE CONCENTRATION FROM MIZEX-87 SAR DATA
}

\author{
Henning Skriver
}

\author{
Electromagnetics Institute, Technical University of Denmark \\ DK-2800 Lyngby Denmark
}

\begin{abstract}
The SAR is an important remote sensor for sea ice applications both by providing detailed maps of small areas and by producing data for calibration of other sensors, e.g. the microwave radiometer. For these applications sea ice type concentration with a high accuracy (better than $5 \%$ ) is needed. This accuracy can normally not be obtained by using the individual pixels, but spatial variation (texture) must be taken into account. An investigation of texture measures to improve the discrimination capability of SAR data from MIZEX ' 87 has been carried out. The classification of the individual ice types is improved considerably by including texture measures, but further development of algorithms is needed to fulfill the requirements.
\end{abstract}

Keywords: sea ice type concentration, synthetic aperture radar, texture, and segmentation.

\section{INTRODUCTION}

Microwave remote sensing is an essential tool for studying large-, medium-, and small-scale sea ice phenomena in polar regions [1]. This is due to the fact that microwave remote sensing is largely independent of light and weather conditions. The synthetic aperture radar (SAR) is essential due to its fine spatial resolution which enables detailed imaging of the scene of observation. The advantage of the microwave radiometer is its large coverage, and even with its coarser resolution it gives accurate estimates of sea ice parameters due to the multiple frequencies and polarizations. Also, visual and infrared data contain very useful information about sea ice in the polar regions. A number of parameters, which is of great importance for research and application purposes may be derived from the remote sensing data. This applies to ice concentration, ice motion, lead structure, floe size distribution, etc. Extraction of sea ice parameters with the required resolution, accuracy, and coverage in time and space is not possible using a single sensor alone, due to the advantages and disadvantages of the individual sensors. Therefore methods that utilize combinations of data from different sensors will be crucial in future remote sensing applications.

The Electromagnetics Institute participates in the Greenland Sea Project developing methods for extraction of geophysical parameters from remote sensing data. Case studies where data for a limited time period can be studied in details are important for this development. The MIZEX 87 period is defined as such a case study, and a large amount of data from NOAA AVHRR, LANDSAT, NIMBUS-7 SMMR, and SAR has been collected, so results from the different data sets can be compared. The MIZEX ' 87 was an experiment in the marginal ice zone of the Greenland Sea (coverage: $75^{\circ} \mathrm{N}-79^{\circ} \mathrm{N}$ and $5^{\circ} \mathrm{W}-5^{\circ} \mathrm{E}$ ), and the experiment included an extensive acquisition of ground data and remote sensing data [2-3]. The objectives of the experiment were to study air-sea-ice processes and to evaluate SAR-data for the study of sea ice. This paper will concentrate on the extraction of sea ice type concentration from SAR data.

The discrimination of different ice types and water in SAR images is the basis of deriving all other parameters. This discrimination is complicated by the inherent speckle noise and by the ambiguities between the backscatter coefficient for some ice types (and water). Therefore, using only the backscattered intensity for ice type discrimination will not result in a sufficient accuracy, and descriptive parameters (e.g. texture parameters) must be included [4-9]. In [9] an extensive study and development of methods for ice parameter extraction on a firm basis of SAR imaging and speckle theory has been carried out using SEASAT and SAR-580 SAR data.This work has in this paper been extended to the MIZEX '87 SAR data.

In the following section the data set is outlined. Hereafter, ice type discrimination using different texture measures is discussed. Then, the method for extraction of ice type concentration is discussed. The final section holds the conclusions.

\section{DATA SET}

The SAR data used were acquired by the Canadian STAR-2 SAR on two missions (16 and 17) on 7 April 1987 [10]. The data are shown in Fig. 1, and they have the following parameters: X-band, $\mathrm{HH}$-polarization, incidence angles $60^{\circ}$ $85^{\circ}$, spatial resolution $15 \mathrm{~m} \times 15 \mathrm{~m}$, swath width of each swath $60 \mathrm{~km}$, and coverage $76^{\circ} \mathrm{N}-79^{\circ} \mathrm{N}$ and $2^{\circ} \mathrm{W}-10^{\circ} \mathrm{W}$. The two swaths on the left side were acquired on mission 16 from about 12:00 to 13:30 (GMT) and the right swath was acquired on mission 17 from about 19:00 to 19:30 (GMT) [10].

The data consist of multiyear ice floes in a first-year ice background on the left and upper part of Fig. 1. The first-year ice areas can be divided into at least three different types: small streaks of rough first-year ice with high return, small areas of 


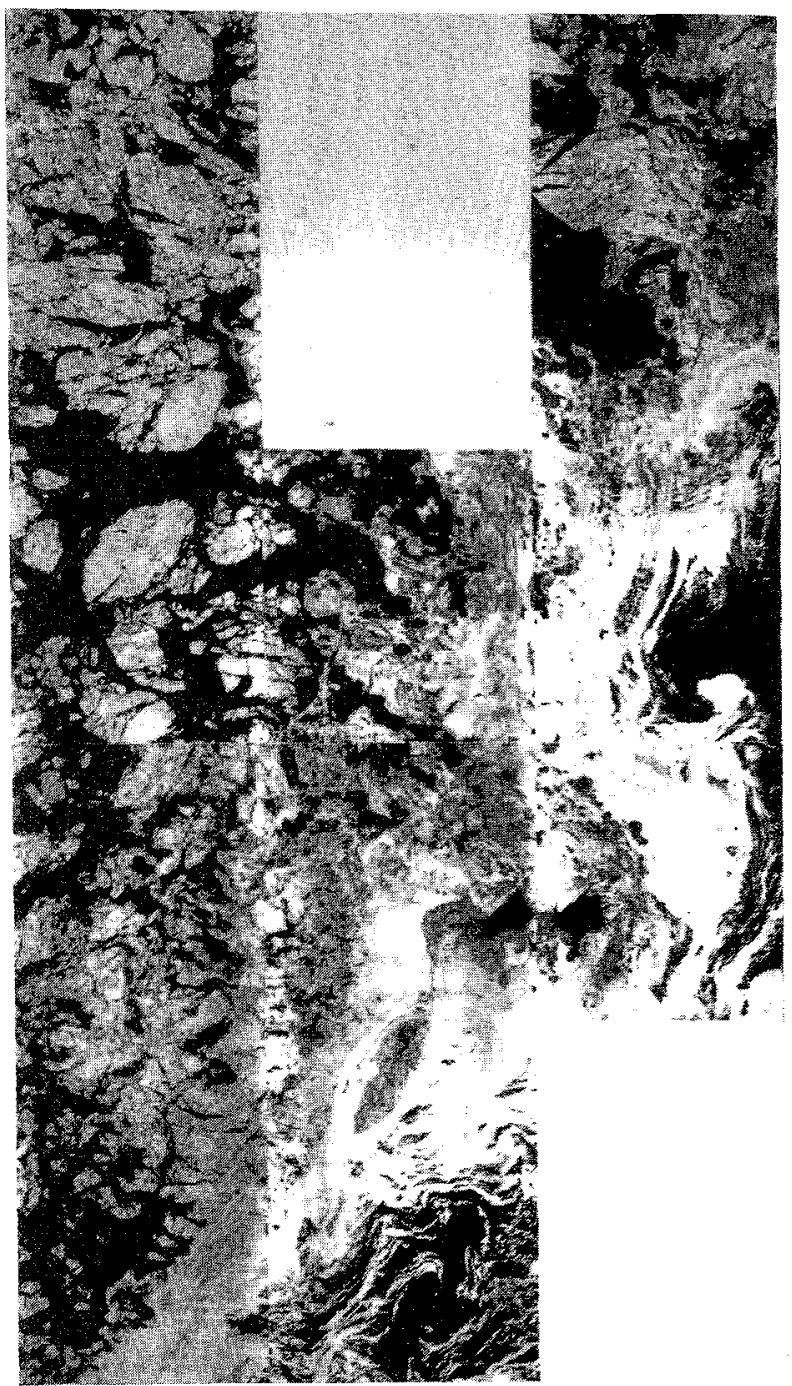

Fig. 1 MIZEX '87 SAR data from 7 April 1987 covering the area from $76^{\circ} \mathrm{N}$ to $79^{\circ} \mathrm{N}$ and from $2^{\circ} \mathrm{W}$ to $10^{\circ} \mathrm{W}$. Credit NRSC and ERIM.

rather smooth first-year ice, and a major part of first-year ice with considerable rafting. A careful study of the data show that there is also small areas of open water in the ice pack. Along the ice edge is seen a band of a mixture of multiyear ice and first-year ice with small floes with diameter of $50-250 \mathrm{~m}$ [10]. The dark area seen on the right part of the image is open water, with nilas on the bottom part.

A large number of areas has been picked from the three swath shown in Fig. 1 representing the different ice types (and water) mentioned above except for the nilas ice which covers areas that are too small to be significant in the analysis of the ice type discrimination capability. The size of the areas is 128 $x 128$ pixels, and they are picked out on the basis of the interpretation done in [10]: A total of 174 areas with $2,850,816$ pixels has been picked, and it is not attempted to select homogeneous areas but representative areas.

\section{ICE TYPE DISCRIMINATION}

The basis of parameter retrieval of any kind is the ability to discriminate between the targets in question. In SAR images the basis of discrimination is the properties of the backscatter coefficient, i.e. the mean backscatter coefficient and the spatial variations in the backscatter coefficient - also called texture. The ability to discriminate between ice types has been studied using a number of measures.

The average intensity for an area is directly related to the average backscatter coefficient, and it is consequently a very important measure. The discrimination capability of the average intensity is shown in Fig. 2 for the ice types in question: Here is shown the average intensity plus/minus one standard deviation vs. area size (i.e. area side length of 60 means area size $60 \times 60$ pixels) where areas with different sizes are obtained by subdividing the original areas. We observe a decrease in the variation with increasing area size as expected due to the speckle reduction. The large variation even for the large areas must be due to uncompensated variations in the mean level for the different swaths and uncompensated effects of the antenna pattern. Large overlaps are seen between the multiyear ice and mixture areas, between first-year and rough first-year ice areas, and between smooth first-year and water areas. So, especially the thin smooth ice cannot be discriminated from the water areas, causing problems for the determination of the ice concentration.

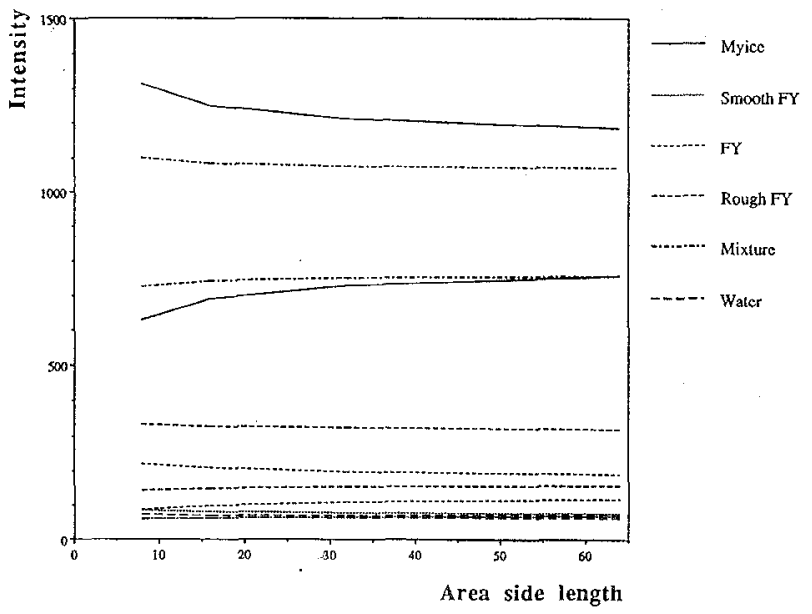

Fig. 2 The average intensity plus/minus one standard deviation vs. area size (area side length $=60$ means area size $=60 \times 60$ pixels)

Also, various first-order and second-order texture measures have been studied. The first-order texture measures used are the power-to-mean ratio (PMR), skewness and kurtosis [9]. The second-order texture measures investigated are the SGLDM-measures (Spatial Grey Level Dependence Method), which is based on estimation of the second-order joint probability density function $[9,11]$. From this pdf a number of texture measures can be computed, e.g. contrast and homogeneity measures. In Fig 3 is shown the SGLDMmeasure SENT (Sum Entropy) with displacement 3 vs. area side length. Using this measure we observe for instance a discrimination between the smooth first-year ice and the water areas for larger areas (larger than $40 \times 40$ pixels). So, this indicates that it may be possible to determine the ice concentration if the leads in the ice pack are sufficiently large.

These SGLDM-measures have been computed for displacements from 1 to 5 pixels. This results in a total of 49 


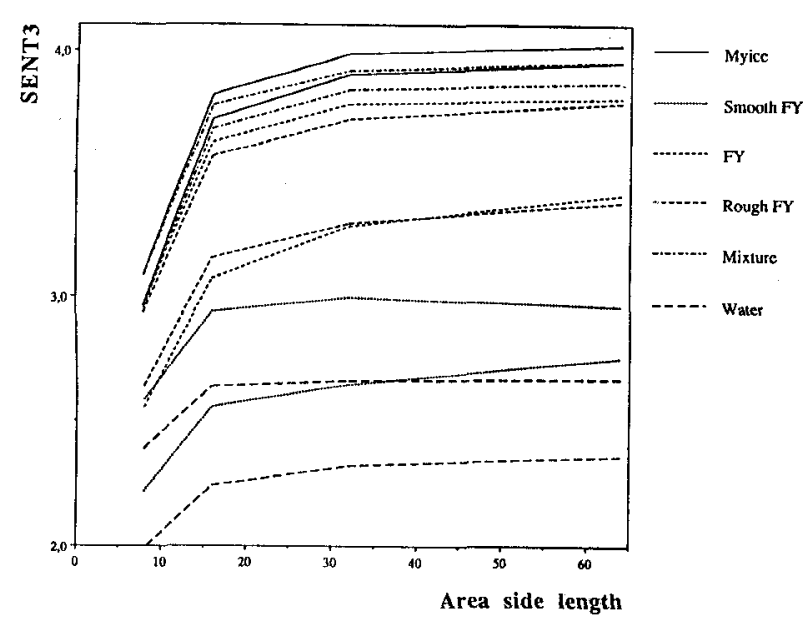

Fig. 3 The SGLDM-measure SENT (Sum Entropy) plus/minus one standard deviation vs. area size for displacement 3 .

parameters to determine the ice type for an area. Of course, these measures are highly correlated. A principal component analysis show that the first 4 principal components contain $95 \%$ of the original variation in the 49 parameters. This high correlation is seen on Fig. 4, where the correlation coefficient between the SENT with displacement 3 and each of the other parameters is shown.

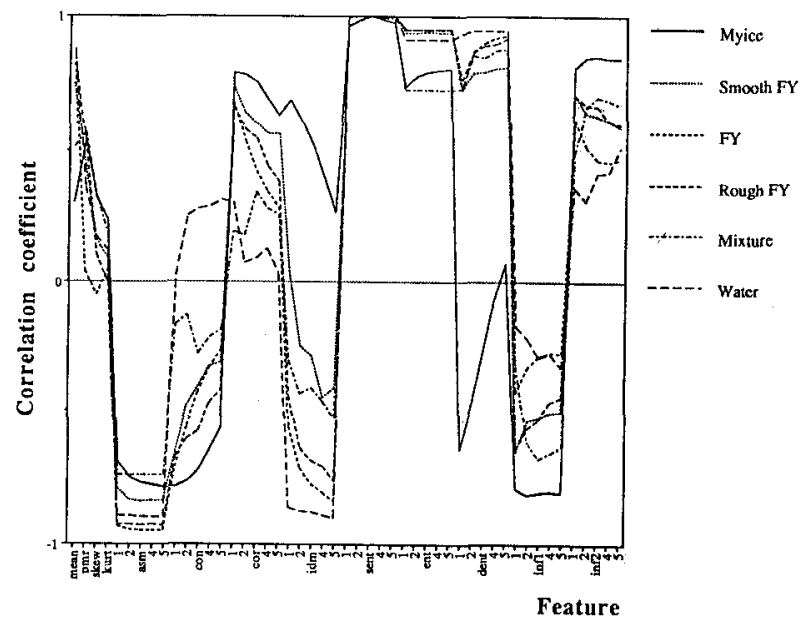

Fig. 4 The correlation coefficients for the individual classes between the SGLDM-measure SENT (Sum Entropy) for displacement 3 and all features for the $64 \times 64$ areas.

Due to the high correlation only a few parameters can be used in the discrimination process. The selection of parameters that "best" discriminate between the classes in the actual data set and thereby form an optimum feature vector is carried out by means of a stepwise discriminant analysis. The discrimination potential of the feature vector is evaluated using a training set test set approach, where the data set is divided into two sets at random. The parameters selected are entered one by one into the feature vector, and the mean probability of error is estimated.

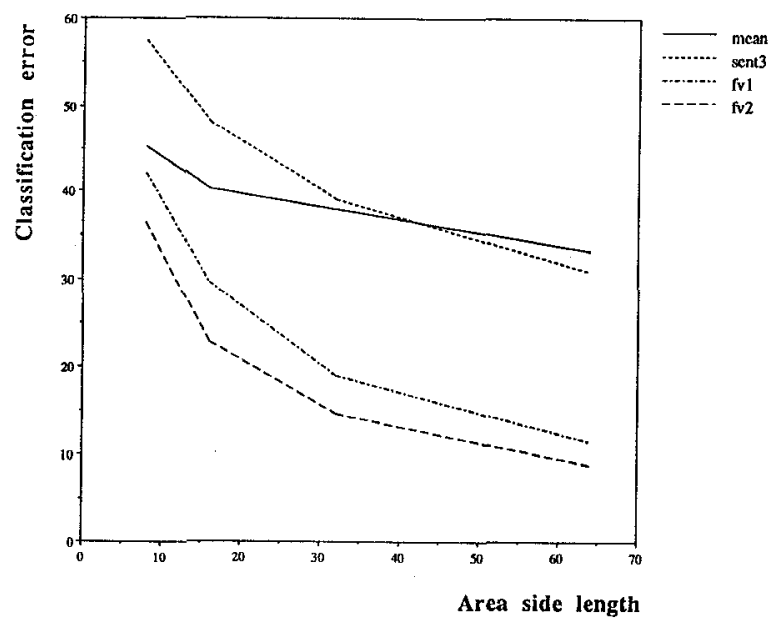

Fig. 5 The estimated probability of error vs. area size for four different feature vectors: mean: average intensity, SENT3: SENT(3), fv1: average intensity and SENT(3), fv2: average intensity, SENT(5), COR(1), and SENT(1).

The average intensity is always forced into the feature vector due to its importance especially for the smaller areas. The estimated mean probability of error vs. area size is shown in Fig. 5 for the average intensity (mean). As expected from the large overlap observed in Fig. 2, the estimated errors are rather large, largest for the smallest areas. The estimated mean probability of error for SENT(3) alone is also shown in Fig. 5 , and it is seen that for larger areas the result is slightly better, whereas for the smaller areas the result is worse.

The selection of the parameters for the feature vector is based on the $64 \times 64$ areas. First, the SGLDM-measures are divided into 5 groups one for each of the 5 displacements. Each of these groups are then used together with the average intensity and the first-order measures in the selection of parameters. In each of the 5 cases the same ranked feature vector for the first 4 parameters is obtained, probably due to the high correlation: average intensity (forced), SENT, COR (correlation), and ENT (entropy). The mean probability of error only decreases when the first texture measure is included (SENT). Including more parameters did not improve the classification result. The mean probability of error for this feature vector is also shown in Fig. 5 (fv1), and a substantial improvement is observed especially for the large areas $(64 \times 64$ pixels: improvement $=$ $22 \%$ ).

Finally, all SGLDM-measures for all displacements (1-5) were used in the selection of parameters. The ranked feature vector obtained is: average intensity (forced), SENT(5), COR(1), and SENT(1). This feature vector gave slightly better results (fv2 in Fig. 5), probably due to the smaller correlation between the SGLDM-measures for different displacements.

\section{ICE TYPE CONCENTRATION}

The algorithm for sea ice concentration runs in a number of steps: First, a segmentation process divides the image into segments each covering an area with the same target type. Hereafter, each segment is classified into one of several target type classes (open water, multiyear ice, etc.). Finally, the ice type concentration can be computed from the classified segments.

The segmentation process also runs in a number of steps [9]: First, an edge detection followed by an edge thinning is 


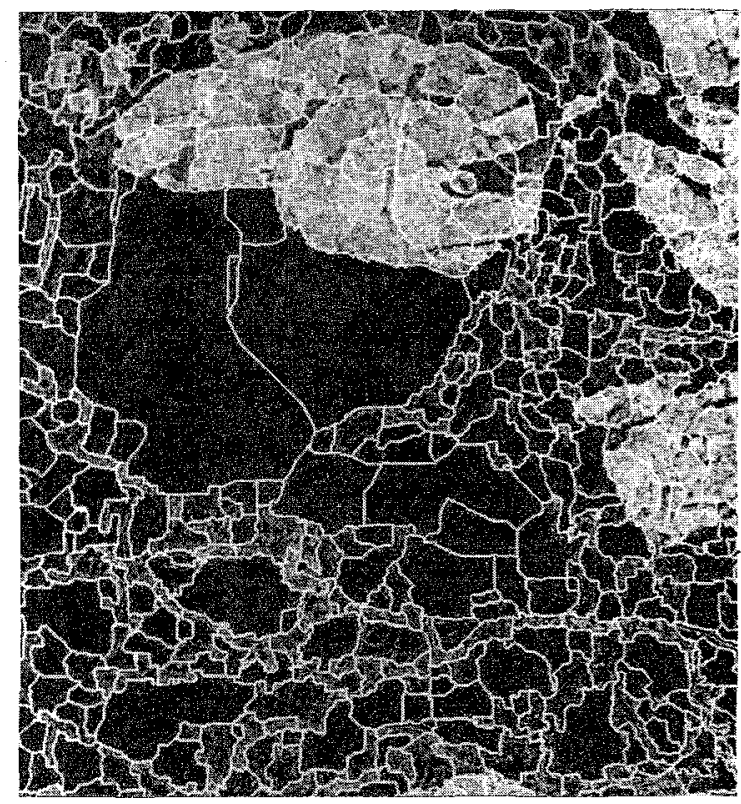

Fig. 6 Segmented $1024 \times 1024$ pixels subset of Fig. 1 .

carried out to determine well-defined edge points at the border of the segments. Hereafter, a region growing algorithm based on the edge points is used for the segmentation. First, a distance transform is used to determine the segment kernels and hereafter the slope of the distance transform is used to link the non-kernel pixels to the segment kernels [9]. The result of applying this algorithm on a $1024 \times 1024$ pixels subset of the MIZEX ' 87 data is shown in Fig. 6. The segments have been manually classified to establish the "correct" class. This manual interpretation shows that segments corresponding to only $2-3 \%$ of the pixels in the image contain more than one ice type, indicating the good performance of the segmentation algorithm.

The segments have then been classified using the feature vectors found in Section 3, and the results have been compared with the manual classification. Using only the average intensity the percentage of misclassified pixels is $22.3 \%$, whereas this figure is reduced to $16.1 \%$ when SENT(3) is included. The results are slightly worse than the result $(6 \%)$ obtained in $[8,9]$ using SAR-580 data. One of the reasons for this difference can be that the manual discrimination between first-year and rough first-year ice in the MIZEX ' 87 data is very difficult, and the transition from one of the ice types to the other is not very sharp. Also, it must be emphasized that this is only results from small subimages and it needs further investigations to obtain representative results.

\section{CONCLUSIONS}

An investigation of the discrimination capability of various texture measures using MIZEX '87 SAR data has been carried out. Both first-order and second-order texture measures have been studied together with the average intensity. Optimum feature vectors have been studied, and they only contain few of the original measures, due to a high correlation. An improvement in the mean classification error of more than $20 \%$ is obtained for large areas ( $64 \times 64$ pixels) when texture measures are included in the feature vector compared to using the average intensity alone. The resulting error for large areas is about $10 \%$. A classification of segments in a subimage resulted in $16 \%$ misclassified pixels.
An important application of the SAR data in the future will be to use them for calibration of other remote sensing data, e.g. microwave radiometers. The calibration of the radiometer data for sea ice applications needs areas with well-determined ice type concentration to compute tie points for the brightness temperatures for different ice types [12]. Comparing qualitatively the MIZEX '87 SAR data with NIMBUS-7 SMMR data shows that the absolute accuracy of the ice concentration estimate from the radiometer data might be improved by $5-10 \%$ by using the SAR data to determine the tie points. However, this needs a mean classification error less than about $5 \%$, so further improvements are necessary.

\section{ACKNOWLEDGEMENTS}

I want to thank very much Ola M. Johannessen and Stein Sandven from the Nansen Remote Sensing Center in Bergen, Norway, for providing the MIZEX'87 SAR data. The work has been carried out under the Greenland Sea Project supported by the Danish Space Board.

\section{REFERENCES}

[1] Carsey, F., "Review and Status of Remote Sensing of Sea Ice", IEEE J. Oceanic Eng., vol. 14, pp. 127-138, 1989.

[2] MIZEX Group "MIZEX East 1987: The Winter Marginal Ice Zone Program in the Fram Strait/Greenland Sea", EOS, vol. 70 pp. 545-555, 1989.

[3] Johannessen, OM S Sandven, T I Olaussen J A Johannessen, R. Karpuz, and H. Flesche, "The pre ERS-1 Experiments MIZEX 87 and SIZEX '89", EARSeL 9th Symposium, Espoo, Finland, pp. 392-397; 1989

[4] Guindon, B., R.K. Hawkins, and D.G. Goodenough, "Spectral Spatial Analysis of Microwave Sea Ice Data", IEEE International Geoscience and Remote Sensing Symposium Digest, pp.TA8.4 $4.8,1982$.

[5] Holmes, Q.A., D.R. Nuesch, and R.A Shuchman, “Textura Analysis and Real-Time Classification of Sea-Ice Types Using Digital SAR Data", IEEE Trans. Geosc. Rem. Sens., vol. GE22, pp. 113-120, 1984

[6] Lyden, J.D., B.A. Burns, and A.L. Maffett, "Characterization of Sea Ice Types Using Synthetic Aperture Radar", IEEE Trans. Geosc. Rem. Sens., vol. GE-22, pp. 431-438, 1984.

[7] Burns, B.A., D.J. Cavalieri, M.R. Keller, W.J. Campbell, T.C Grenfell , G.A. Maykut, and P. Gloersen, "Multisensor Comparison of Ice Concentration Estimates in the Marginal Ice Zone", J. Geophys. Res., vol. 92, pp. 6843-6856, 1987.

[8] Skriver, H., "Determination of Sea Ice Parameters from SAR Data", EARSeL 9th Symposium, Espoo, Finland, pp. 143-148, 1989.

[9] Skriver, H., "Extraction of Sea Ice Parameters from Synthetic Aperture Radar Images", Ph.D. thesis, LD 74, Electromagnetics Institute, Technical University of Denmark, 335 pp., 1989

[10] Shuchman, R.A., L.L. Sutherland, B.A, Burns, and E.D. Leavitt, MIZEX 1987 SAR Data Summary, Environmental Research Institute of Michigan, 1988.

[11] Haralick, R.M., K.S. Shanmugan, and I. Dinstein, "Textura Features for Image Classification", IEEE Trans. Syst:, Man Cybern., vol. SMC-3 pp. 610-621, 1973.

[12] Pedersen, L.T., "Retrieval of Sea Ice Concentration by Means of Microwave Radiometry", Ph.D. thesis, LD 81 Electromagnetics Institute, Technical University of Denmark, 148 pp., 1991. 